\title{
Lama menderita diabetes mellitus tipe 2 sebagai faktor risiko neuropati perifer diabetik
}

\author{
Galvani Volta Simanjuntak ${ }^{1 *}$, Marthalena Simamora ${ }^{2}$ \\ 1,2Program Studi Ners Universitas Sari Mutiara Indonesia. *Email: galvanisimanjuntak@yahoo.co.id
}

\begin{abstract}
Sensory neuropathy in type 2 diabetes mellitus and its correlation with duration of disease
\end{abstract}

Background: Diabetic peripheral neuropathy is a complication of type 2 diabetes mellitus (T2DM) that results in harm to the nervous system. It is a progressive disease, and symptoms get worse over time.

Purpose: To exploration the sensory neuropathy in type 2 diabetes mellitus and its correlation with duration of disease.

Method: An observational analytic with cross sectional design with population was patients with T2DM without diabetic ulcers in diabetic clinic Sari Mutiara Hospital. The number of samples was 86 respondents by a simple random sampling. Measuring the risk of diabetic peripheral neuropathy used 10 gram monofilament.

Results: Showed the majority of the duration of T2DM $>5$ years $(53,5 \%)$ and the majority of respondents had neuropathy $(54,7 \%)$. The results of the Spearman rank correlation test showed that there was a significant correlation between duration of T2DM and risk of diabetic peripheral neuropathy ( $p$-value $=0,023$ and $r=-0,438$ ).

Conclusion: The majority respondents has a diabetic peripheral neuropathy and also has a risk of diabetic peripheral neuropathy who are suffering $>5$ years. It is recommended that they need a regularly asses and educate to prevent further complication.

\section{Keywords: Sensory neuropathy; Type 2 diabetes mellitus; Duration of disease}

Pendahuluan: Neuropati perifer diabetes adalah komplikasi diabetes yang mengakibatkan kerusakan sistem saraf. Ini adalah penyakit progresif, dan gejalanya bertambah buruk seiring waktu.

Tujuan: Untuk mengetahui hubungan lama menderita dengan risiko neuropati pada pasien DM tipe 2.

Metode: Desain analitik korelasi dengan pendekatan cross sectional dan populasinya seluruh pasien DM tipe 2 yang tidak memiliki ulkus diabetik di klinik diabetes RSU Sari Mutiara. Sampelnya sebanyak 86 yang diambil dengan teknik simple random sampling. Risiko neuropati perifer diabetik diukur menggunakan monofilament 10 gram.

Hasil: Analisis data menunjukkan mayoritas pasien menderita DM tipe 2 yang $>5$ tahun $(53,5 \%)$ dan mayoritas pasien telah mengalami neuropati $(54,7 \%)$. Hasil uji statistik menggunakan korelasi spearman menunjukan adanya hubungan lama menderita DM tipe 2 dengan risiko neuropati $(p$-value $=0,023<0,05$ dan nilai $r=$ $-0,438)$.

Simpulan: Mayoritas responden yang mengalami Neuropati perifer diabetes maupun resiko terjadinya Neuropati perifer diabetes pada mereka kelompok yang menderita DM tipe 2 yang $>5$ tahun. Sangat dianjurkan pada pasien tersebut untuk dilakukan pengkajian secara teratur dan pendidikan untuk mencegah komplikasi lebih lanjut.

\section{Kata Kunci : Lama menderita; Diabetes mellitus tipe 2; Neuropati Perifer}

\section{PENDAHULUAN}

Diabetes Mellitus tipe II merupakan penyakit degeneratif yang sampai saat ini masih sulit ditangani. Hal ini disebabkan karena Diabetes Mellitus tipe II (DM Tipe II) memiliki berbagai faktor risiko mulai dari gaya hidup, aktifitas fisik serta pola makan yang kurang baik yang memang cenderung sulit untuk dikontrol secara komprehensif sehingga angka kejadian DM tipe II terus meningkat (Lathifah, 2017; Handajani, 2010). Tahun 2017, jumlah penderita DM di seluruh dunia sebanyak 425 juta dan diprediksi meningkat menjadi 629 juta pada tahun 2045. Indonesia menempati urutan ke6 sebagai negara dengan jumlah penderita DM terbanyak yaitu sebanyak 10,3 juta (International Diabetes Federation, 2017). Hasil Riskesdas tahun 
Lama menderita diabetes mellitus tipe 2 sebagai faktor risiko neuropati perifer diabetik

2018 menunjukkan terjadi peningkatan penderita DM dari 6,9\% pada tahun 2013 menjadi 8,5\% (data berdasarkan konsesus perkeni 2011), atau menjadi 10,9\% (data berdasarkan konsesus 2015) pada tahun 2018 (Kementerian Kesehatan Republik Indonesia, 2019).

Diabetes mellitus tipe II adalah penyakit yang ditandai dengan kadar gula darah yang tinggi. Kadar gula darah tinggi dalam waktu yang lama akan merusak pembuluh saraf tepi sehingga proses pengiriman sinyal antara sistem saraf pusat dan sistem saraf tepi terganggu. Gangguan ini disebut dengan neuropati perifer diabetik dan hampir $30 \%$ penderita DM mengalami neuropati (Pranata, 2017; Prasetyo \& Aetyaningsih, 2011). Akibat neuropati perifer diabetik, kepekaan rangsangan terhadap suhu dan nyeri semakin menurun. Hal ini memperbesar resiko pasien mengalami ulkus kaki (Soegondo, Soewondo, \& Subekti, 2014).

Neuropati perifer diabetik sering tidak menimbulkan tanda dan gejala khas sehingga hampir $50 \%$ pasien DM Tipe II tidak menyadari menderita ini. Untuk itu, identifikasi tanda-tanda awal neuropati, diagnosis dini, dan manajemen yang tepat ditahap awal sangat penting sehingga tidak berkembang menjadi ulkus kaki diabetik (Danjo, Danjo, Sawada, Uchida, \& Nakamura, 2018). Pentingnya deteksi dan pengobatan dini pada neuropati perifer karena saraf perifer memiliki kemampuan terbatas untuk berregenerasi. Dengan deteksi dini perkembangan kerusakan saraf perifer dapat dihambat/dihentikan. Salah satu upaya deteksi dini yang dapat dilakukan adalah dengan melakukan pemeriksaan sensasi menggunakan 10 gr monofilament test (Perkumpulan Endokrinologi Indonesia, 2015; Pop-Busui, Boulton, Feldman, Bril, Freeman, Malik, \& Ziegler, 2017; Brown, Pribesh, Baskette, Vinik, \& Colberg, 2017). Penderita DM tipe II yang memiliki sensasi normal di kaki biasanya dapat merasakan sentuhan monofilamen, tetapi pada penderita yang diduga memiliki penurunan sensitivitas kaki atau kehilangan sensitivitas kaki tidak dapat merasakan sentuhan monofilament.

Penelitian membuktikan bahwa ada hubungan yang signifikan antara lama menderita diabetes mellitus dengan terjadinya neuropati sensorik diabetic, dan di laporkan bahwa tidak ada hubungan yang bermakna antara durasi menderita
DM dengan angka kejadian neuropati diabetik (Lestari, 2015; Andatu, 2016).

\section{METODE PENELITIAN}

Penelitian ini menggunakan desain analitik korelasi dengan pendekatan cross sectional. Populasinya adalah seluruh pasien DM tipe 2 yang tidak memiliki ulkus kaki yang menjalani rawat jalan di Klinik Diabetes RSU Sari Mutiara. Jumlah sampelnya sebanyak 86 responden yang diambil menggunakan teknik simple random sampling. Pengukuran risiko neuropati dilakukan dengan menggunakan $10 \mathrm{gr}$ monofilament. Sebelum dilakukan penilaian, Monofilamen $10 \mathrm{gr}$ terlebih dahulu diujicobakan pada sternum atau dahi dengan tujuan agar responden dapat mengenal sensasi rasa dari sentuhan monofilamen. Pemeriksaan dilakukan di telapak kaki responden dengan 4 titik area di masing-masing kaki. Pada masing-masing titik area dilakukan tiga kali pemeriksaan, jika responden terindikasi tidak merasakan monofilament. Nilai hasil pemeriksaan monofilamen ditentukan berdasarkan ada atau tidak adanya sensasi rasa yang dipersepsikan oleh responden saat monofilamen $10 \mathrm{~g}$ disentuhkan di telapak kaki subjek. Nilai 1 jika tekanan dipersepsikan sama saat dilakukan di sternum atau dahi, nilai 0,5 jika tekanan dirasakan tetapi tidak sekuat tekanan yang diraskan jika tes dilakukan di dahi atau sternum, dan nilai 0 jika tekanan tidak dirasakan. Setelah semua titik diperiksa, maka jumlahkan hasil penilaian dari 8 titik. Nilai 3 dikategorikan telah terjadi neuropati, nilai 3,5-5 dikategorikan resiko tinggi terjadi neuropati, dan nilai 5,5-8 dikategorikan resiko rendah terjadi neuropati. Sebelumnya peneliti sudah mendapatkan surat layak etik dari komite Etik Penelitian Kesehatan Fakultas Kedokteran Universitas Muhammadiyah Sumatera Utara dan dinyatakan lolos uji etik dengan nomor surat 398/KEPK/FKUMSU/2019. Data yang telah terkumpul akan dianalisis menggunakan uji korelasi spearman dengan $a=0,05$. 
HASIL

Tabel 1. Distribusi Karakteristik Responden $\mathrm{N}=86$

\begin{tabular}{lcc}
\hline Variabel & Frekuensi (f) & Persentase (\%) \\
\hline $\begin{array}{l}\text { Jenis Kelamin } \\
\quad \text { Laki-laki }\end{array}$ & 36 & \\
$\quad$ Perempuan & 50 & 41,9 \\
Usia & & 58,1 \\
$\quad$ 5 45 tahun & 3 & \\
$\quad>45$ tahun & 83 & 3,5 \\
& & 96,5 \\
Lama Menderita DM Tipe 2 & & \\
$\quad$ 5 tahun & 40 & \\
$\quad$ 5 tahun & 46 & 56,5 \\
& & \\
Neuropati & & \\
$\quad$ Telah terjadi neuropati & 47 & 54,7 \\
$\quad$ Risiko tinggi terjadi neuropati & 24 & 27,9 \\
$\quad$ Risiko rendah terjadi neuropati & 15 & 17,4 \\
\hline
\end{tabular}

Hasil penelitian mendapatkan bahwa mayoritas responden berjenis kelamin perempuan $(58,1 \%)$ dengan usia $>45$ tahun $(96,5 \%)$ dan menderita DM tipe 2 selama $>5$ tahun $(53,5 \%)$ serta telah mengalami neuropati $(54,7 \%)$.

Tabel 2. Hasil Analisis Uji Korelasi Spearman

\begin{tabular}{lcccccc}
\hline Lama menderita DM & \multicolumn{3}{c}{ Neuropati } & Total & p-value & $\mathbf{r}$ \\
\cline { 2 - 5 } & $\begin{array}{c}\text { Sudah } \\
\text { Neuropati } \\
(\mathbf{n})\end{array}$ & $\begin{array}{c}\text { Resiko } \\
\text { tinggi } \\
(\mathbf{n})\end{array}$ & $\begin{array}{c}\text { Resiko } \\
\text { rendah } \\
(\mathbf{n})\end{array}$ & $(\mathbf{N})$ & & \\
\hline$\leq 5$ tahun & 20 & 10 & 10 & 40 & & \\
$>5$ tahun & 27 & 14 & 5 & 46 & 0,023 & $-0,438$ \\
\multicolumn{1}{c}{ TOTAL } & 47 & 24 & 15 & 86 & & \\
\hline
\end{tabular}

Hasil penelitian memperoleh bahwa dari 46 responden yang menderita DM tipe $\|>5$ tahun, 27 responden telah terjadi neuropati, 14 respoden beresiko tinggi terjadi neuropati dan 5 responden beresiko rendah terjadi neuropati. Hasil uji korelasi spearman mendapatkan nilai pValue $0,023(<0,05)$ dengan nilai $r-0,438$ yang berarti ada hubungan signifikan lama menderita DM tipe II dengan resiko terjadinya neuropati. Keeratan hubungan lemah dan berpola negatif (semakin lama menderita DM tipe II maka semakin rendah sensitifitas kaki responden. Rendahnya sensitifitas kaki akan meningkatkan resiko terjadinya neuropati.

\section{PEMBAHASAN}

Mayoritas responden pada penelitian ini adalah perempuan hampir sama dengan penelitian sebelumnya juga menemukan bahwa mayoritas penderita DM Tipe II adalah perempuan (Fadhilah, 2016; Isnaini \& Ratnasari, 2018). Hal ini dipertegas dari hasil Riskesdas tahun 2018 yang melaporkan bahwa penderita DM di Indonesia lebih banyak perempuan dibandingkan laki-laki (Kementerian Kesehatan Republik Indonesia, 2019). Banyak faktor penyebab tingginya angka kejadian DM pada wanita seperti genetik, gaya hidup, kurangnya aktifitas fisik, obesitas hingga riwayat diabetes gestasional dan riwayat melahirkan bayi dengan berat badan $>4000$ gram (Nuryanti \& 
Lama menderita diabetes mellitus tipe 2 sebagai faktor risiko neuropati perifer diabetik

Bantas, 2014). Faktor lain yang mempengaruhi tingginya angka kejadian DM pada wanita adalah perubahan hormonal dan psikologis yang dialami wanita akibat fase siklus menstruasi, kehamilan dan menyusui sehingga perempuan memiliki resiko lebih besar untuk menderita DM tipe 2 dibandingkan laki-laki, berhubungan dengan kehamilan dimana kehamilan merupakan faktor resiko untuk terjadinya penyakit diabetes mellitus (Tandra, 2014).

Berdasarkan hasil analisis data didapatkan bahwa mayoritas responden berusia $>45$ tahun. Penelitian lain juga melaporkan bahwa mayoritas penderita DM tipe 2 berusia $>45$ tahun dan didukung hasil Riskesdas 2018 juga mendapatkan bahwa penyakit DM di Indonesia lebih banyak diderita pada usia $>45$ tahun dengan rentang usia yang dominan adalah 55-64 tahun dan 65-74 tahun (Fadhilah, 2016; Isnaini \& Ratnasari, 2018; Kementerian Kesehatan Republik Indonesia, 2019). Risiko untuk menderita intoleransi glukosa meningkat seiring dengan meningkatnya usia, Perkumpulan Endokrinologi Indonesia (Perkeni) menganjurkan untuk melakukan pemeriksaan DM pada pasien dengan usia $>45$ tahun karena umumnya diabetes terjadi pada usia $>45$ tahun. Hal ini dikarenakan proses penuaan menyebabkan kurangnya sel beta pankreas dalam memproduksi insulin (American Heart Association, 2015; Perkumpulan Endokrinologi Indonesia, 2015).

Hasil penelitian menunjukkan ada hubungan lama menderita denga risiko neuropati perifer pada pasien DM tipe 2. Semakin lamanya seseorang menderita DM, semakin besar resiko terkena neuropati, dimana lamanya menderita DM dengan kadar glukosa darah yang tinggi dapat melemahkan dan merusak dinding pembuluh darah kapiler yang memvaskularisasi saraf sehingga terjadi kerusakan saraf yaitu neuropati (Tandra, 2014).

Proses terjadinya neuropati biasanya progresif. Kadar gula darah tinggi dalam waktu yang lama menyebabkan penimbunan sorbitol yang meningkatkan aktivitas jalur poliol dan berakibat pada perubahan jaringan saraf. Perubahan ini berdampak pada gangguan transduksi sinyal pada saraf yang menyebabkan penderita DM tipe II mengalami penurunan sensitivitas di kaki (Ardiyati, 2014). Hal ini menyebabkan kurangnya kepekaan terhadap rangsangan nyeri, panas, trauma mekanis dan diabetisi tidak menyadari bahwa telah mengalami beberapa tipe trauma kaki yang menyebabkan terjadinya ulkus kaki (Susilowati \& Windawati, 2016).

\section{SIMPULAN}

Berdasarkan hasil penelitian dapat disimpulkan bahwa ada hubungan signifikan lama menderita DM tipe II dengan resiko terjadinya neuropati. Semakin lama menderita DM tipe II maka semakin rendah sensitifitas kaki responden. Rendahnya sensitifitas kaki akan meningkatkan resiko terjadinya neuropati perifer diabetik pada pasien DM tipe II.

\section{SARAN}

Bagi pasien DM tipe II perlu melakukan pemeriksaan sensitifitas kaki menggunakan monofilament secara rutin sehingga neuropati perifer bisa dicegah. Bagi perawat disarankan melakukan monofilament test pada pasien DM tipe II serta memberikan pendidikan kesehatan mengenai pencegahan dan deteksi dini neuropati perifer diabetik sejak awal pasien terdiagnosa DM tipe II.

\section{DAFTAR PUSTAKA}

American Heart Association. (2015). Understand Your Risk for Diabetes. Retrieved from American Heart Association:

https://www.heart.org/en/healthtopics/diabetes/understand-your-risk-for-diabetes.

Andatu, R, L. (2016). Hubungan Antara Durasi Menderita Diabetes Mellitus (DM) Dengan Angka Kejadian Neuropati Diabetik (Thesis, Universitas Muhammadiyah Yogyakarta).

Ardiyati, A.V.(2014). Hubungan Antara Skor Monofilamen Dengan Ulkus Diabetik Di Klinik Perawatan Luka Rumat Bekasi. (Skripsi tidak dipublikasi). Program Studi IImu Keperawatan Fakultas Kedokteran dan IImu Kesehatan Universitas Islam Negeri Syarif Hidayatullah, Jakarta.

Brown, J. J., Pribesh, S. L., Baskette, K. G., Vinik, A. I., \& Colberg, S. R. (2017). A Comparison of Screening Tools for the Early Detection of Peripheral Neuropathy in Adults with and without Type 2 Diabetes. Journal of diabetes research, 2017, 1467213. 
Danjo, J., Danjo, S., Sawada, H., Uchida, K., \& Nakamura, Y. (2018). Diabetic neuropathy: a focus on the testing method. International Journal of Family \& Community Medicine, 2(1), $1-5$.

Fadhilah, M. (2016). Gambaran Tingkat Risiko dan Faktor-faktor yang Berhubungan dengan Risiko Diabetes Mellitus Tipe 2 di Buaran, Serpong. YARSI Medical Journal, 24(3), 186202.

Handajani, A., Roosihermatie, B., \& Maryani, H. (2010). Faktor-faktor yang berhubungan dengan pola kematian pada penyakit degeneratif di Indonesia. Buletin penelitian sistem kesehatan, 13(1), 42-53.

International Diabetes Federation. (2017). IDF Diabetes Atlas (8 $8^{\text {th }}$ Edition). Brussels: International Diabetes Federation.

Isnaini, N., \& Ratnasari, R. (2018). Faktor risiko mempengaruhi kejadian Diabetes mellitus tipe dua. Jurnal Kebidanan dan Keperawatan Aisyiyah, 14(1), 59-68.

Kementerian Kesehatan Republik Indonesia. (2019). Infodatin: Hari Diabetes Sedunia Tahun 2018. Jakarta: Pusat Data Dan Informasi Kemenkes $\mathrm{RI}$ https://pusdatin.kemkes.go.id/download.php?fil e=download/pusdatin/infodatin/infodatinDiabetes-2018.pdf

Lathifah, N. L. (2017). Hubungan durasi penyakit dan kadar gula darah dengan keluhan subyektif penderita diabetes mellitus. Jurnal berkala epidemiologi, 5(2), 231-239.

Lestari, D. (2015). Hubungan Antara Lama Menderita Diabetes Mellitus Tipe 2 Dengan Terjadinya Neuropati Sensorik Diabetik Di RSUD Salatiga Surakarta: Skripsi program studi ilmu kedokteran Universitas Muhammadiyah Surakarta.
Nuryanti, I., \& Bantas, K. (2014). Prevalensi dan Faktor Risiko Kejadian Diabetes Mellitus Pada Wanita Dewasa di Indonesia. (Thesis, Universitas Indonesia).

Perkumpulan Endokrinologi Indonesia. (2015). Konsesus Pengelolaan dan Pencegahan Diabetes Mellitus Tlpe 2 di Indonesia. Jakarta: PB Perkeni. https://pbperkeni.or.id/wpcontent/uploads/2019/01/4.-KonsensusPengelolaan-dan-Pencegahan-Diabetesmellitus-tipe-2-di-Indonesia-Perkeni-2015.pdf

Pop-Busui, R., Boulton, A. J., Feldman, E. L., Bril, V., Freeman, R., Malik, R. A., \& Ziegler, D. (2017). Diabetic neuropathy: a position statement by the American Diabetes Association. Diabetes care, 40(1), 136-154.

Pranata, S. (2017). Perbedaan Tingkat Kecemasan Pada Pasien Diabetes Mellitus Dengan Neuropati Perifer Yang Diberikan Intervensi Tens Dan Intervensi Nafas Dalam Saat Dilakukan Perawatan Ulkus Kaki Diabetik Di Rsud Kota Yogyakarta. Jurnal Keperawatan dan Pemikiran IImiah, 3(2), 11-19.

Prasetyo, G. A., \& Aetyaningsih, I. (2011). Lama Menderita Diabetes Mellitus Tipe 2 Sebagai Faktor Risiko Nyeri Neuropati Diabetik (Doctoral dissertation, Universitas Gadjah Mada).

Soegondo, S., Soewondo, P., \& Subekti, I. (2014). Penatalaksanaan diabetes mellitus terpadu. Jakarta: Balai Penerbit FKUI.

Susilowati, T., \& Windawati, F. (2016). Senam Ergonomik Meningkatkan Sensitivitas Kaki Pada Penderita Diabetes Mellitus Di Kelurahan Purwosari Kecamatan Laweyan Kota Surakarta. Jurnal Maternity, 3(2).

Tandra, H. (2014). Strategi Mengalahkan Komplikasi Diabetes Dari Kepala Sampai Kaki. Jakarta: PT Gramedia Pustaka Utama. 